\title{
COMPORTAMENTO DE CULTIVARES DE SOJA EM FUNÇÃO DE ÉPOCAS DE SEMEADURA
}

\author{
Eduardo Gazola ${ }^{1}$, Leandro Borges Lemos ${ }^{2}$, Rogério Farinelli ${ }^{2}$, Cláudio Cavariani ${ }^{3}$ \\ ' Coordenadoria de Assistência Técnica Integral (CATI), Núcleo de Produção de Sementes "Ataliba Leonel”, CEP 18780-000, \\ Manduri, SP. E-mail: eduardo.gazola@cati.sp.gov.br \\ ${ }^{2}$ Universidade Estadual Paulista (UNESP), Faculdade de Ciências Agrárias e Veterinárias, Departamento de Produção Vegetal, \\ CEP 14884-900, Jaboticabal, SP. E-mail: leandrobl@fcav.unesp.br, rfarinelli@fcav.unesp.br. \\ ${ }^{3}$ Universidade Estadual Paulista (UNESP), Faculdade de Ciências Agronômicas, Departamento de Produção Vegetal, CEP \\ 18610-307 Botucatu, SP. E-mail: ccavariani@fca.unesp.br
}

\section{RESUMO}

A definição da época de semeadura e a correta utilização de cultivares são fundamentais para obtenção de altos rendimentos de grãos na cultura da soja, por isso o objetivo do trabalho foi avaliar as características agronômicas de seis cultivares de soja (Embrapa 48, BRS 183, BRS 133, BRS 184, BRS 215 e Conquista) em duas épocas de semeadura (15/10 e 15/11), durante as safras de 2003/04 e 2004/05, num esquema fatorial 6 × 2, com quatro repetições. Na safra 2003/04, a época de semeadura em novembro proporcionou maior produtividade quando comparada a outubro devido principalmente ao número de vagens por planta, destacando-se com produtividade de grãos acima de $3.200 \mathrm{~kg} \mathrm{ha}^{-1}$ as cultivares Embrapa 48, BRS 133, BRS 215 e Conquista. Na safra 2004/05 não houve diferença entre as épocas, sendo que todas as cultivares alcançaram patamares superiores a $3.000 \mathrm{~kg} \mathrm{ha}^{-1}$.

Palavras-chave: Glycine max, variedades, componentes da produção, produtividade

\section{BEHAVIOR OF SOYBEAN CULTIVARS IN FUNCTION OF SOWING DATES}

\begin{abstract}
The definition of the sowing dates and the correct use of cultivars is basic for attainment of high incomes of soybean grains. The objective of this work was to evaluate the agronomic characteristic of six soybean cultivars (Embrapa 48, BRS 183, BRS 133, BRS 184, 215 BRS and Conquista) at two sowing dates (October, 15 and November, 15), in a factorial design $6 \times 2$, with four replications. In the harvest of 2003/04, the sowing date in November provided higher yield when compared to October due mainly to the number of pods per plant, with the cultivars Embrapa 48 , BRS $133,215 \mathrm{BRS}$ and Conquista reaching productivity above $3,200 \mathrm{~kg} \mathrm{ha}^{-1}$. As to the 2004/05 harvest no diferences were observed between the dates, for all the cultivars reached values superior to $3,000 \mathrm{~kg} \mathrm{ha}^{-1}$.
\end{abstract}

Key words: Glycine max, varieties, yield components, productivity 


\section{INTRODUÇÃO}

A expansão da cultura da soja (Glycine max) no território nacional, deve-se ao intenso trabalho do melhoramento genético com o lançamento no mercado agrícola de diversas cultivares, tendo por parte da pesquisa a função de realizar a avaliação daquelas mais promissoras para cada sistema de produção (Embrapa, 2005).

Para se obter altos rendimentos na cultura da soja é importante o conhecimento de práticas culturais compatíveis com a produção econômica, sendo fundamentais a correta escolha da cultivar, aliada a época de semeadura mais adequada para cada região de cultivo. O potencial produtivo de uma cultura pode ser definido em função da produção da cultivar em ambiente a qual está devidamente adaptada sem limitações edafoclimáticas, nutricionais e sob ausência de problemas fitossanitários.

\section{A soja apresenta características} fisiológicas de uma planta fotossensível, ou seja, é sensível a extensão do período de ausência de luz para a indução floral e posterior desenvolvimento. Diante desta característica, a faixa de adaptabilidade de cada cultivar varia à medida que desloca-se ao norte ou ao sul do país (Rodrigues et al., 2001). Assim, a avaliação do comportamento agronômico das cultivares de soja em diferentes épocas de semeadura numa determinada região é de suma importância na indicação do período mais favorável ao crescimento visando principalmente o aumento de produtividade (Bonato et al.,1998; Motta et al., 2000).

Em virtude da produtividade ser muito influenciada por fatores ambientais, como o comprimento do dia e temperatura, tem-se designado que a época ideal de semeadura no Brasil, de maneira geral, é de $1^{\circ}$ a 15 de novembro. A sua antecipação ou atraso pode acarretar queda de produtividade nas cultivares atualmente disponíveis, o que tem incentivado os programas de melhoramento a desenvolver genótipos adaptados a um período mais amplo de semeadura, ou seja, de setembro a dezembro (Martins et al., 1999; Prado et al., 2001; Bonato et al., 2001; Carvalho et al., 2002; Barros et al., 2003).

Segundo Martins et al. (1999) a época de semeadura provoca alterações nos componentes da produção e nas características morfológicas da soja, afetando o porte da planta, a inserção de vagens, o número de ramifícações e o grau de acamamento. Braccini et al. (2004) relataram que a redução no número de dias para o florescimento e maturação das plantas, quando se retardou a semeadura de $15 / 11,15 / 01$ e 15/02 foi responsável pela diminuição na altura de planta e inserção da primeira vagem, no número de vagens por planta, massa de grãos e produtividade das cultivares BRS 132 (ciclo precoce), BRS 133 e BR 16 (ciclo semiprecoce), BRS 134 (ciclo médio) e FT-Estrela (ciclo tardio), sendo a mais produtiva a BRS 133 , com $3.462 \mathrm{~kg} \mathrm{ha}^{-1}, 1.799 \mathrm{~kg} \mathrm{ha}^{-1}$ e $933 \mathrm{~kg} \mathrm{ha}^{-1}$, nas três épocas avaliadas, respectivamente.

Bonato et al. (1998) verificaram que as produtividades de grãos obtidas nas semeaduras de outubro e de novembro foram semelhantes no grupo de cultivares de ciclo precoce e semitardio/tardio, enquanto que a semeadura de novembro foi superior a de meados de outubro nas cultivares de ciclo médio. Peixoto et al. (2000) em vista dos resultados obtidos, concluíram que cultivar de ciclo médio foi a melhor adaptada nas semeaduras na época normal (12/11), tardia $(19 / 12)$ e safrinha (18/03) em comparação a cultivares precoce e semi-precoce. De acordo com Motta et al. $(2000,2002) \mathrm{em}$ semeaduras efetuadas na segunda quinzena de outubro os patamares de produtividade média de grãos foram superiores de $3.879 \mathrm{~kg}$ $\mathrm{ha}^{-1}$ e $3.520 \mathrm{~kg} \mathrm{ha}^{-1}$, respectivamente, destacando-se principalmente as cultivares BRS 133 (4.059 $\mathrm{kg} \mathrm{ha}^{-1}$ ) e BRS 134 (4.340 $\mathrm{kg} \mathrm{ha}^{-1}$ ). 
O objetivo deste trabalho foi avaliar o comportamento de cultivares de soja em diferentes épocas de semeadura, quanto às características agronômicas nas safras 2003/04 e 2004/05.

\section{MATERIAL E MÉTODOS}

Os experimentos foram conduzidos nas safras 2003/04 e 2004/05, na Faculdade de Ciências Agronômicas, UNESP, campus de Botucatu (SP), apresentando latitude de $22^{\circ} 51^{\prime} \mathrm{S}$, longitude de $48^{\circ} 26^{\prime} \mathrm{W}$, altitude de 786 metros, num Nitossolo Vermelho, com teores de areia, silte e argila de 245, 105 e $650 \mathrm{~g} \mathrm{~kg}^{-1}$, respectivamente. Segundo a classificação de Köppen, o clima do local é do tipo $\mathrm{Cfa}$, definido como temperado (mesotérmico), com verões quentes e úmidos, e invernos frios e secos, tendo quatro ou mais meses com temperatura média superiore a $10^{\circ} \mathrm{C}$, cuja temperatura do mês mais quente é igual ou superior a $22^{\circ} \mathrm{C}$.

Os dados mensais referentes à temperatura máxima e mínima, e precipitação pluvial durante a realização dos experimentos encontram-se na Figura 1. Os atributos químicos do solo da área na profundidade de $0-20 \mathrm{~cm}$ revelaram os seguintes resultados para $\mathrm{pH}\left(\mathrm{CaCl}_{2}\right)=5,5$; $\mathrm{P}$ resina $\left(\mathrm{mg} \mathrm{dm}{ }^{-3}\right)=14 ; \mathrm{K} ; \mathrm{Ca} ; \mathrm{Mg} ; \mathrm{H}+\mathrm{Al}$; $\mathrm{SB} ; \mathrm{CTC}=0,6 ; 46,0 ; 14,0 ; 31,0 ; 60,0 ; 91,0 \mathrm{e}$ $\mathrm{V}(\%)=66 . \mathrm{Na}$ adubação de semeadura nas duas safras foram empregados $340 \mathrm{~kg} \mathrm{ha}^{-1}$ do formulado 4-20-20.

\section{Precip. $\rightarrow-\mathrm{T} \min . \rightarrow \mathrm{T}$ máx.}

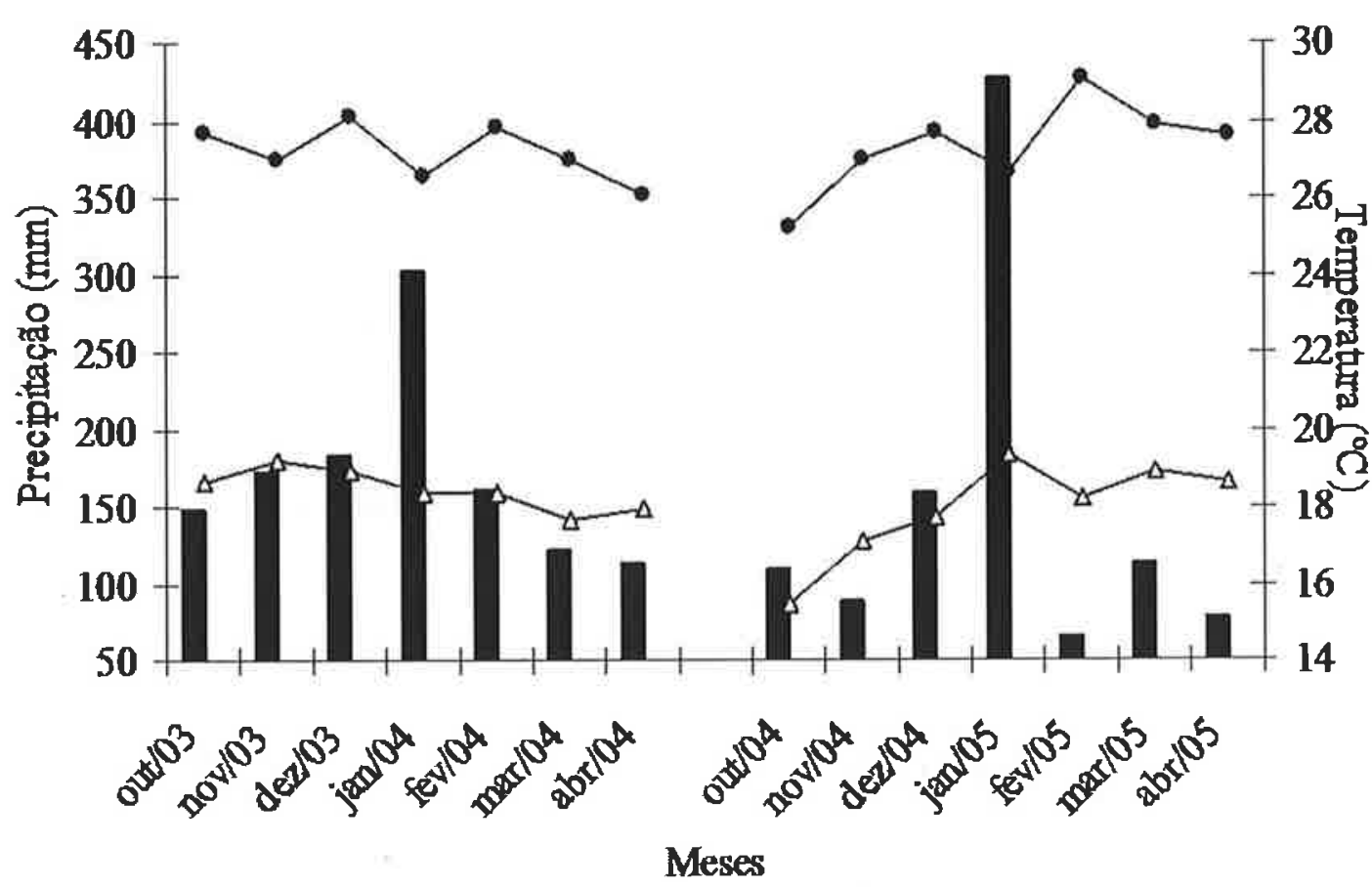

Figura 1. Precipitação pluvial acumulada, temperatura mínima e máxima durante o desenvolvimento das cultivares nas épocas de semeadura. Botucatu (SP), 2003/04 e 2004/05. 
Antecedendo a instalação dos experimentos procedeu-se a escarificação da área com o objetivo de eliminar camadas de impedimento físico. Visando realizar um sistema de sucessão de culturas foi implantada nos anos de 2003 e 2004 a cultura de aveia preta (cultivar Comum) no período de outono-inverno, sendo manejada aos 70 dias após a emergência das plântulas, por meio de dessecação com glyphosate na dose de 2,5 $\mathrm{L} \mathrm{ha}^{-1}$ de produto comercial. O preparo do solo da área experimental foi caracterizado por cultivo mínimo nas duas safras.

O tratamento de sementes consistiu de fungicida carboxin + thiram, Co $(0,01 \%)$ + Mo (2,5\%) e inoculante líquido nas doses comerciais de $250 \mathrm{~mL}, 250 \mathrm{~mL}$ e $300 \mathrm{~mL}$ por $100 \mathrm{~kg}$ de sementes, respectivamente. Os demais tratamentos fitossanitários foram realizados mediante aplicação de produtos recomendados à cultura da soja.

O delineamento experimental utilizado foi o de blocos casualizados dispostos em esquema fatorial $6 \times 2$, com quatro repetições. Os tratamentos constituíram de seis cultivares de soja (Embrapa 48 e BRS 183 de ciclo precoce, BRS 133 e BRS 184 de ciclo semi-precoce e BRS 215 e Conquista de ciclo médio), semeadas em duas épocas (15/10 e 15/11). As parcelas experimentais foram representadas por 5 linhas de $5 \mathrm{~m}$ de comprimento espaçadas em $0,45 \mathrm{~m}$, considerando como área útil as três linhas centrais eliminando-se $0,50 \mathrm{~m}$ das extremidades de cada linha. A densidade de semeadura para as cultivares foi de 22 sementes por metro, visando obter uma população final de 300.000 plantas $^{-1} \mathrm{a}^{-1}$.

Durante o desenvolvimento das cultivares nas duas épocas de semeadura foram avaliados o número de dias para o florescimento, compreendido entre a emergência das plântulas (VE) até $50 \%$ das plantas no estádio R1, ou seja, plantas com pelo menos uma flor aberta na haste principal. A maturação fisiológica referiu-se ao período entre a emergência das plântulas até $50 \%$ das plantas no estádio R8, ou seja, maturação plena (Ferh et al., 1971).

No final do ciclo de cada cultivar foram coletadas 10 plantas ao acaso na área útil da parcela experimental, objetivando avaliar o grau de acamamento utilizando a escala de notas variando de 1 a 5 , sendo: $1=$ $0 \%$ ou nenhuma planta acamada, $2=25 \%$ de plantas acamadas, $3=50 \%$ de plantas acamadas, $4=75 \%$ de plantas acamadas e 5 $=100 \%$ de plantas acamadas. Também foi determinada a altura de planta e de inserção da primeira vagem, número de vagens por planta, número de grãos por vagem e massa de 100 grãos.

A produtividade de grãos foi obtida através do auxílio de colhedora automotriz própria para experimentos, transformando os valores em $\mathrm{kg} \mathrm{ha}^{-1}$ a $13 \% \mathrm{em}$ base úmida.

Os resultados nas duas safras foram submetidos à análise de variância através do teste $\mathrm{F}$, com as médias comparadas pelo teste de Tukey a 5\% de probabilidade, e na presença de interação significativa entre os fatores cultivares $\mathrm{x}$ épocas de semeadura procederam-se os desdobramentos necessários.

\section{RESULTADOS E DISCUSSÃO}

Os resultados para o florescimento pleno e maturação fisiológica estão coerentes com as descrições das cultivares quanto ao ciclo de desenvolvimento (Embrapa, 2005), sendo que as mais precoces foram exatamente a BRS 183 e Embrapa 48, ciclo semi-precoce as cultivares BRS 184 e BRS 133, e médio para BRS 215 e Conquista. Quanto à época de semeadura, todas as cultivares necessitaram de maior tempo para florescer e conseqüentemente 
maior período para atingir a maturação fisiológica quando semeadas em 15/10 nas duas safras (Tabelas 1 e 2), mantendo suas características de juvenilidade, confirmando os resultados de Martins et al. (1999) e Braccini et al. (2004).

Tabela 1. Interação significativa do número de dias para o florescimento de cultivares de soja em função de épocas de semeadura. Botucatu (SP), 2003/04 e 2004/05.

\begin{tabular}{|c|c|c|c|c|}
\hline \multirow{3}{*}{ Cultivares } & \multicolumn{3}{|c|}{$2003 / 04$} & $2004 / 05$ \\
\hline & \multicolumn{4}{|c|}{ Épocas de semeadura } \\
\hline & $15 / 10$ & $15 / 11$ & $15 / 10$ & $15 / 11$ \\
\hline Embrapa 48 & $50 \mathrm{cA}$ & $46 \mathrm{cB}$ & $49 \mathrm{dA}$ & $44 \mathrm{~dB}$ \\
\hline BRS 183 & $51 \mathrm{cA}$ & $46 \mathrm{cB}$ & $51 \mathrm{dA}$ & $43 \mathrm{~dB}$ \\
\hline BRS 133 & $56 \mathrm{bA}$ & $51 \mathrm{bB}$ & $56 \mathrm{cA}$ & $47 \mathrm{cB}$ \\
\hline BRS 184 & $56 \mathrm{bA}$ & $47 \mathrm{cB}$ & $56 \mathrm{cA}$ & $45 \mathrm{bB}$ \\
\hline Conquista & $62 \mathrm{aA}$ & $54 \mathrm{aB}$ & $64 \mathrm{aA}$ & $55 \mathrm{aB}$ \\
\hline BRS 215 & $61 \mathrm{aA}$ & $53 \mathrm{abB}$ & $61 \mathrm{bA}$ & $54 \mathrm{aB}$ \\
\hline DMS $^{(1)}$ & \multicolumn{2}{|c|}{2,04} & \multicolumn{2}{|c|}{1,90} \\
\hline DMS $^{(2)}$ & \multicolumn{2}{|c|}{1,37} & \multicolumn{2}{|c|}{1,30} \\
\hline
\end{tabular}

Médias seguidas de letras distintas minúsculas nas colunas e maiúsculas nas linhas diferem entre si pelo teste de Tukey a 5\%. ${ }^{(1)}$ Cultivares dentro de épocas, ${ }^{(2)}$ Épocas dentro de cultivares.

Tabela 2. Interação significativa do número de dias para a maturação físiológica de cultivares de soja em função de épocas de semeadura. Botucatu (SP), 2003/04 e 2004/05.

\begin{tabular}{|c|c|c|c|c|}
\hline \multirow{3}{*}{ Cultivares } & \multicolumn{3}{|c|}{$2003 / 04$} & $2004 / 05$ \\
\hline & \multicolumn{4}{|c|}{ Épocas de semeadura } \\
\hline & $15 / 10$ & $15 / 11$ & $15 / 10$ & $15 / 11$ \\
\hline Embrapa 48 & $133 \mathrm{cA}$ & $124 \mathrm{~dB}$ & $134 \mathrm{eA}$ & $120 \mathrm{eB}$ \\
\hline BRS 183 & $129 \mathrm{dA}$ & $122 \mathrm{~dB}$ & $128 \mathrm{dA}$ & $119 \mathrm{eB}$ \\
\hline BRS 133 & $139 \mathrm{bA}$ & $129 \mathrm{cB}$ & $138 \mathrm{cA}$ & $131 \mathrm{cB}$ \\
\hline BRS 184 & $138 \mathrm{bA}$ & $131 \mathrm{cB}$ & $139 \mathrm{cA}$ & $125 \mathrm{~dB}$ \\
\hline Conquista & $151 \mathrm{aA}$ & $143 \mathrm{aB}$ & $158 \mathrm{aA}$ & $146 \mathrm{aB}$ \\
\hline BRS 215 & $152 \mathrm{aA}$ & $140 \mathrm{bB}$ & $152 \mathrm{bA}$ & $143 \mathrm{aB}$ \\
\hline DMS $^{(1)}$ & \multicolumn{2}{|c|}{2,68} & \multicolumn{2}{|c|}{2,18} \\
\hline DMS $^{(2)}$ & \multicolumn{2}{|c|}{1,80} & \multicolumn{2}{|c|}{1,47} \\
\hline
\end{tabular}

Médias seguidas de letras distintas minúsculas nas colunas e maiúsculas nas linhas diferem entre si pelo teste de Tukey a $5 \% .{ }^{(1)}$ Cultivares dentro de épocas, ${ }^{(2)}$ Épocas dentro de cultivares.

A redução em número de dias para estes materiais quando se retardou a semeadura justifica os efeitos da temperatura e do fotoperíodo, onde existe um determinado limite de comprimento de dia suficientemente curto para induzir a floração e longo para impedí-la (Rodrigues et al.,
2001). A sensibilidade ao fotoperíodo é característica varietal, onde cada cultivar possui o seu fotoperíodo crítico, acima do qual o florescimento é atrasado. Segundo Wang et al. (1998) a correta previsão da duração entre a emergência e a floração determina ainda a produção de matéria seca 
e conseqüentemente o potencial de rendimento.

Para a altura de planta e de inserção da primeira vagem, os efeitos da época de semeadura e das cultivares em 2003/04 (Tabela 3), como da interação significativa em 2004/05 (Tabela 4) mostraram valores compatíveis para a colheita mecanizada, sendo que a semeadura efetuada em 15/11 na safra 2004/05 (Tabela 4) resultou em alturas de plantas mais expressivas para todas as cultivares estudadas, assemelhando-se aos resultados obtidos por Martins et al. (1999) em semeadura em época normal (12/11). De acordo com Rezende \& Carvalho (2007) e Garcia et al. (2007), a altura de plantas compreendida entre 50 a $120 \mathrm{~cm}$, com inserções de vagem de pelo menos 10 a 12 $\mathrm{cm}$ se torna adequadas à mecanização da colheita.

A diferença em relação ao porte de planta e altura de vagens está fortemente relacionada com as cultivares de soja. Motta et al. (2000) avaliando cultivares de ciclos de desenvolvimento distintos observaram que as mais tardias apresentavam maior altura de planta, provavelmente em virtude do período maior para o desenvolvimento e crescimento vegetativo. Tal resultado foi semelhante para a cultivar Conquista, que obteve maior altura de planta nas duas épocas de semeadura (Tabela 4). Especificamente para a altura de inserção da primeira vagem pode ocorrer grande variabilidade de valores, estabelecendo entre 15 a $38 \mathrm{~cm}$, o que foi comprovado por Prado et al. (2001) para as cultivares FT Estrela e Milionária.

Tabela 3. Altura de planta $(\mathrm{cm})$, altura de inserção de $1^{\mathrm{a}}$ vagem $(\mathrm{cm})$, número de vagens por planta e número de grãos por vagem de cultivares de soja semeadas em duas épocas. Botucatu (SP), 2003/04 e 2004/05.

\begin{tabular}{cccccc}
\hline Avaliações & $\begin{array}{c}\text { Altura de } \\
\text { plantas }\end{array}$ & $\begin{array}{c}\text { Altura de } \\
\text { inserção de } \\
\mathbf{1}^{\mathrm{a}} \text { vagem }\end{array}$ & $\begin{array}{c}\text { Vagens por } \\
\text { planta }\end{array}$ & \multicolumn{2}{c}{$\begin{array}{c}\text { Grãos por } \\
\text { vagem }\end{array}$} \\
Safras & --------- 2003/04 ---------- & $\mathbf{2 0 0 3 / 0 4}$ & $\mathbf{2 0 0 4 / 0 5}$ \\
\hline Cultivares & $75 \mathrm{bc}$ & $12 \mathrm{~b}$ & $54 \mathrm{~b}$ & $1,9 \mathrm{~b}$ & $1,7 \mathrm{bc}$ \\
Embrapa 48 & $61 \mathrm{~d}$ & $14 \mathrm{ab}$ & $47 \mathrm{~b}$ & $2,1 \mathrm{ab}$ & $1,8 \mathrm{abc}$ \\
BRS 183 & $69 \mathrm{c}$ & $13 \mathrm{~b}$ & $62 \mathrm{~b}$ & $2,1 \mathrm{ab}$ & $1,9 \mathrm{abc}$ \\
BRS 133 & $72 \mathrm{bc}$ & $14 \mathrm{ab}$ & $82 \mathrm{a}$ & $2,0 \mathrm{ab}$ & $1,6 \mathrm{c}$ \\
BRS 184 & $86 \mathrm{a}$ & $17 \mathrm{a}$ & $55 \mathrm{~b}$ & $2,6 \mathrm{a}$ & $2,1 \mathrm{ab}$ \\
Conquista & $80 \mathrm{ab}$ & $17 \mathrm{a}$ & $46 \mathrm{~b}$ & $2,4 \mathrm{ab}$ & $2,2 \mathrm{a}$ \\
BRS 215 & $66 \mathrm{~b}$ & $14 \mathrm{a}$ & $52 \mathrm{~b}$ & $2,1 \mathrm{a}$ & $1,8 \mathrm{a}$ \\
\hline Épocas & $81 \mathrm{a}$ & $14 \mathrm{a}$ & $63 \mathrm{a}$ & $2,3 \mathrm{a}$ & $1,9 \mathrm{a}$ \\
\hline $\mathbf{1 5 / 1 0}$ & 7,1 & 17,5 & 20,4 & 20,0 & 16,6 \\
\hline $\mathbf{1 5 / 1 1}$ & CV (\%) & &
\end{tabular}

Médias seguidas de letras distintas diferem entre si pelo teste de Tukey a 5\%. 
Tabela 4. Interação significativa de altura de planta $(\mathrm{cm})$, altura de inserção de $1^{\mathrm{a}}$ vagem $(\mathrm{cm})$ e número de vagens por planta de cultivares de soja em função de épocas de semeadura. Botucatu (SP), 2004/05.

\begin{tabular}{|c|c|c|c|c|c|c|}
\hline \multirow{3}{*}{ Cultivares } & \multicolumn{2}{|c|}{ Altura de planta } & \multicolumn{2}{|c|}{$\begin{array}{l}\text { Altura de inserção de } \\
\qquad 1^{\mathrm{a}} \text { vagem }\end{array}$} & \multicolumn{2}{|c|}{ Vagens por planta } \\
\hline & \multicolumn{6}{|c|}{ Épocas de semeadura } \\
\hline & $15 / 10$ & $15 / 11$ & $15 / 10$ & $15 / 11$ & $15 / 10$ & $15 / 11$ \\
\hline Embrapa 48 & $77 \mathrm{bB}$ & $103 \mathrm{bA}$ & $12 \mathrm{cB}$ & $19 \mathrm{abA}$ & $73,6 \mathrm{aA}$ & $48,8 \mathrm{aB}$ \\
\hline BRS 183 & $72 \mathrm{bB}$ & $86 \mathrm{cA}$ & $17 \mathrm{abB}$ & $24 \mathrm{aA}$ & $49,4 \mathrm{bcA}$ & $27,7 \mathrm{aB}$ \\
\hline BRS 133 & $75 \mathrm{bB}$ & $85 \mathrm{cA}$ & $17 \mathrm{abA}$ & $18 \mathrm{bA}$ & $38,7 \mathrm{cA}$ & $40,4 \mathrm{aA}$ \\
\hline BRS 184 & $79 \mathrm{bB}$ & $104 \mathrm{bA}$ & $16 \mathrm{bcB}$ & $24 \mathrm{aA}$ & $67,4 \mathrm{abA}$ & $35,1 \mathrm{aB}$ \\
\hline Conquista & $98 \mathrm{aB}$ & $115 \mathrm{aA}$ & $21 \mathrm{aA}$ & $24 \mathrm{aA}$ & $33,6 \mathrm{cA}$ & 30,5 aA \\
\hline BRS 215 & $81 \mathrm{bB}$ & $93 \mathrm{bcA}$ & $18 \mathrm{abA}$ & $21 \mathrm{abA}$ & $40,4 \mathrm{cA}$ & $39,0 \mathrm{aA}$ \\
\hline $\mathbf{D M S}^{(1)}$ & \multicolumn{2}{|c|}{11,60} & \multicolumn{2}{|c|}{5,40} & \multicolumn{2}{|c|}{23,71} \\
\hline $\mathbf{D M S}^{(2)}$ & \multicolumn{2}{|c|}{7,18} & \multicolumn{2}{|c|}{3,60} & \multicolumn{2}{|c|}{19,33} \\
\hline
\end{tabular}

Médias seguidas de letras distintas minúsculas nas colunas e maiúsculas nas linhas diferem entre si pelo teste de Tukey a 5\%. ${ }^{(1)}$ Cultivares dentro de épocas, ${ }^{(2)}$ Épocas dentro de cultivares.

O acamamento é outro fator importante na obtenção de ganhos em produtividade, podendo estar relacionado com a altura da planta. O maior crescimento das plantas na segunda época, nas duas safras, refletiu diretamente no grau de acamamento, que em média apresentou $50 \%$ (safra 2003/04) e 25\% (safra 2004/05) de plantas acamadas (Tabela 5). $\mathrm{O}$ acamamento nas cultivares de soja pode causar redução da produtividade devido o tombamento de plantas próximas ao solo, fazendo com que a barra de corte da colhedora não consiga atingí-las.

Tabela 5. Acamamento, massa de 100 grãos (g) e produtividade de grãos ( $\mathrm{kg} \mathrm{ha}^{-1}$ ) de cultivares de soja semeadas em duas épocas. Botucatu (SP), 2003/04 e 2004/05.

\begin{tabular}{ccccccc}
\hline Avaliações & \multicolumn{2}{c}{ Acamamento } & \multicolumn{2}{c}{ Massa de 100 grãos } & \multicolumn{2}{c}{ Produtividade de grãos } \\
& & & & & & \\
Safras & $\mathbf{2 0 0 3 / 0 4}$ & $\mathbf{2 0 0 4 / 0 5}$ & $\mathbf{2 0 0 3 / 0 4}$ & $\mathbf{2 0 0 4 / 0 5}$ & $\mathbf{2 0 0 3 / 0 4}$ & $\mathbf{2 0 0 4 / 0 5}$ \\
\hline Cultivares & & & & & & \\
Embrapa 48 & 2 & 1 & $17,4 \mathrm{c}$ & $17,1 \mathrm{c}$ & $3.443 \mathrm{a}$ & $3.287 \mathrm{a}$ \\
BRS 183 & 1 & 1 & $18,7 \mathrm{~b}$ & $18,4 \mathrm{bc}$ & $2.551 \mathrm{~b}$ & $3.269 \mathrm{a}$ \\
BRS 133 & 2 & 1 & $17,4 \mathrm{c}$ & $19,3 \mathrm{ab}$ & $3.367 \mathrm{a}$ & $3.162 \mathrm{a}$ \\
BRS 184 & 2 & 2 & $20,3 \mathrm{a}$ & $19,2 \mathrm{bc}$ & $2.909 \mathrm{ab}$ & $3.205 \mathrm{a}$ \\
Conquista & 2 & 2 & $19,0 \mathrm{~b}$ & $21,4 \mathrm{a}$ & $3.292 \mathrm{a}$ & $3.106 \mathrm{a}$ \\
BRS 215 & 2 & 1 & $18,1 \mathrm{bc}$ & $20,0 \mathrm{ab}$ & $3.304 \mathrm{a}$ & $3.064 \mathrm{a}$ \\
\hline É pocas & & & & & & \\
15/10 & 1 & 1 & $18,7 \mathrm{a}$ & $19,2 \mathrm{a}$ & $2.751 \mathrm{~b}$ & $3.241 \mathrm{a}$ \\
$\mathbf{1 5 / 1 1}$ & 3 & 1 & $18,3 \mathrm{a}$ & $19,3 \mathrm{a}$ & $3.538 \mathrm{a}$ & $3.124 \mathrm{a}$ \\
\hline CV (\%) & - & - & 4,8 & 7,3 & 11,8 & 14,4 \\
\hline
\end{tabular}

Médias seguidas de letras distintas diferem entre si pelo teste de Tukey a $5 \%$. 
O retardamento na época de semeadura promoveu redução no número de vagens por planta na safra 2003/04 (Tabela 3), fato já observado por Motta et al. (2000). Nesta safra destaca-se a cultivar BRS 184 pela obtenção de maior número de vagens por planta, como também maior massa de 100 grãos. Na interação significativa para a safra 2004/05 (Tabela 4), os resultados mostraram que a Embrapa 48 destacou-se positivamente na primeira época de semeadura, apresentando 73 vagens por planta. De modo geral, esta época de semeadura proporcionou os maiores valores para este componente da produção, em virtude das melhores condições climáticas durante esta fase de desenvolvimento (Figura 1). Vale ressaltar que mesmo com o maior número de vagens por planta, a cultivar descrita anteriormente obteve valores menos expressivos principalmente quanto à massa de 100 grãos (Tabela 5).

Apesar da massa de grãos não diferir entre as épocas de semeadura estudadas (Tabela 5), a produtividade em 2003/04 apresentou grande diferença, o que pode ser explicado em virtude das condições favoráveis para ao aumento do tamanho do grão, nem sempre são as mesmas para a produção, e apesar da massa de grão influenciar na produtividade, existem outros fatores com maior contribuição, como o número de vagens por planta, grãos por vagem, altura de plantas, número de nós na haste principal e dias para a maturação fisiológica (Medina et al., 1997; Carvalho et al., 2002).

Este fato pode ser observado para as cultivares nas duas safras, onde a Embrapa 48 apesar ter alcançado uma das melhores produtividades de grãos $(3.443$ e $3.287 \mathrm{~kg}$ $\mathrm{ha}^{-1}$, respectivamente), destacando-se quanto ao número de vagens por planta, obteve menor massa de 100 grãos e menor número de grãos por vagem, diferentemente da cultivar Conquista que sobressaiu em relação ao número de grãos por vagem (Tabela 3), mas ao mesmo tempo obteve um desempenho inferior em termos de produtividade média em comparação as demais cultivares estudadas (Tabela 5). Portanto, pode-se inferir que a importância relativa de cada componente da produção pode variar conforme a cultivar, semelhante ao verificado por Navarro Júnior \& Costa (2002).

$\mathrm{Na}$ safra 2003/04, a semeadura realizada em 15/11 promoveu uma produtividade de $787 \mathrm{~kg} \mathrm{ha}^{-1}$ superior a de 15/10 (Tabela 5), conseqüência da maior altura de planta aliada a obtenção de maior número de vagens por planta. Em relação às cultivares, destacaram-se a Embrapa 48 (precoce) e BRS 133 (semi-precoce), BRS 215 e Conquista (médio) com valores acima de $3.200 \mathrm{~kg} \mathrm{ha}^{-1}$. Produtividades superiores no mês de novembro também foram estabelecidas por Bonato et al. (1998) para cultivares de ciclo médio, por Prado et al. (2001) em semeadura efetuada em 15/11, como também por Braccini et al. (2004) obtendo valor de $3.462 \mathrm{~kg} \mathrm{ha}^{-1}$ para a cultivar BRS 133 na mesma data de semeadura descrita anteriormente.

Na safra 2004/05, apesar da grande irregularidade de precipitação pluvial, caracterizada principalmente pelo grande volume em janeiro $(428 \mathrm{~mm})$ associado a uma redução expressiva em fevereiro (66 $\mathrm{mm})$, atingindo temperatura máxima próxima a $30^{\circ} \mathrm{C}$ e mínima em torno de $18^{\circ} \mathrm{C}$ (Figura 1), não houve distinção quanto às épocas, tendo obtido patamares superiores a $3.000 \mathrm{~kg} \mathrm{ha}^{-1}$ de grãos para todas as cultivares (Tabela 5). É importante ser salientado que o valor de produtividade verificado nesta safra também se deve ao manejo adequado da cultura, destacando-se o emprego de sucessão com gramínea, atributos químicos do solo, principalmente quanto à acidez, teores de cálcio, magnésio, saturação por bases e cultivo em área sem 
impedimento físico.

Da mesma maneira, Peixoto et al. (2000) verificaram que o rendimento de grãos nas épocas de semeadura normal $(12 / 11)$ e tardia (19/12) foram semelhantes com as cultivares de soja produzindo aproximadamente duas vezes mais grãos em relação à safrinha, sendo que a cultivar de ciclo médio foi a mais adaptada às condições de cultivo nas épocas avaliadas. Em outros trabalhos, a maior produtividade média em semeaduras na segunda quinzena de outubro alcançou $3.879 \mathrm{~kg} \mathrm{ha}^{-1}$ e $3.520 \mathrm{~kg} \mathrm{ha}^{-1}$ (Motta et al., 2000, 2002), destacando-se principalmente as cultivares BRS 133 (4.059 $\mathrm{kg} \mathrm{ha}^{-1}$ ) e BRS 134 (4.340 $\mathrm{kg} \mathrm{ha}^{-1}$ ).

\section{CONCLUSÕES}

$\mathrm{Na}$ safra 2003/04, a época de semeadura em $15 / 11$ proporcionou maior produtividade quando comparada a 15/10, devido principalmente ao número de vagens por planta, destacando-se com produtividade de grãos acima de $3.200 \mathrm{~kg} \mathrm{ha}^{-1}$ as cultivares Embrapa 48, BRS 133, BRS 215 e Conquista.

Na safra 2004/05 não houve distinção entre as épocas, sendo que todas as cultivares alcançaram patamares superiores a $3.000 \mathrm{~kg} \mathrm{ha}^{-1}$.

\section{REFERÊNCIAS BIBLIOGRÁFICAS}

BARROS, H.B.; PELUZIO, J.M.; SANTOS, M.M.dos.; BRITO, E.L.; ALMEIDA, R.D.de., 2003. Efeito das épocas de semeadura no comportamento de cultivares de soja, no sul do Estado do Tocantins. Revista Ceres, Viçosa, 50: 565-572.

BONATO, E.R.; BERTAGNOLLI, P.F.; IGNACZAK, J.C.; TRAGNAGO, J.L.; RUBIN, S. DE A.L., 1998. Desempenho de cultivares de soja em três épocas de semeadura, no Rio Grande do Sul. Pesquisa Agropecuária Brasileira, Brasília, 33: 879-884.

BONATO, E.R.; LANGE, C.E.; BERTAGNOLLI, P.F., 2001. Desempenho de cultivares de soja de diferentes ciclos em semeaduras de dezembro, na região do planalto médio do Rio Grande do Sul. Ciência Rural, Santa Maria, 31: 935-940.

BRACCINI, A.D.L.; MOTTA, I.D.S.; SCAPIM, C.A.; BRACCINI, M.D.C.L.; ÁVILA, M.R.; MESCHEDE, D., 2004. Características agronômicas e rendimento de sementes de soja na semeadura realizada no período de safrinha. Bragantia, Campinas, 63: 81-92.

CARVALHO, C.G.P. de; ARIAS, C.A.A.; TOLEDO, J.F.F.de; OLIVEIRA, M.F.de; VELLO, N.A., 2002. Correlação e análise de trilha em linhagens de soja semeadas em diferentes épocas. Pesquisa Agropecuária Brasileira, Brasília, 37: 311-320.

EMBRAPA., 2005. Empresa Brasileira de Pesquisa Agropecuária. Tecnologias de produção de soja - região Central do Brasil - 2005. Londrina: Embrapa Soja: Embrapa Cerrados: Embrapa Agropecuária Oeste: Fundação Meridional, 239p.

FEHR, W.R.; CAVINESS, C.E.; GURMOOD, D.T.; PENNINGTON, J.S., 1971. Stage of development description for soybean, Glycine max (L.) Merrill. Crop Science, Madison, 11: 929-931.

GARCIA, A.; PÍPOLO, A.E.; LOPES, I.O.N.; PORTUGAL, F.A.F., 2007. Instalação da lavoura de soja: época, cultivares, espaçamento e população de plantas. Londrina: Embrapa Soja. 11p. (Circular Técnica, 51).

MARTINS, M.C.; CÂMARA, G.M.S.; 
PEIXOTO, C.P.; MARCHIORI, L.F.S.; LEONARDO, V.; MATTIAZZI., 1999. Épocas de semeadura, densidade de plantas e desempenho vegetativo de cultivares de soja. Scientia Agrícola, Piracicaba, 54: 851-858.

MEDINA, P.F.; RAZERA, L.F.; FILHO, J.M.; BORTOLETTO, N., 1997. Produção de sementes de cultivares precoces de soja em duas épocas e dois locais paulistas: I. Características agronômicas e produtividade. Bragantia, Campinas, 56: 291-303.

MOTTA, I. DE M.; BRACCINI, A. DE L.E.; SCAPIM, C.A.; GONÇALVES, A.C.A.; BRACCINI, M. DO L., 2000. Característica agronômicas e componentes da produção de sementes de soja em diferentes épocas de semeadura. Revista Brasileira de Sementes, Brasília, 22: 153-162.

MOTTA, I. DE S.; BRACCINI, A. DE L.E.; SCAPIM, C.A.; INOUE, M.H.; ÁVILA, M.R.; BRACCINI, M. DO L., 2002. Época de semeadura em cinco cultivares de soja. I. Efeito nas características agronômicas. Acta Scientiarum, Maringá, 24: 1275-1280.

NAVARRO JÚNIOR, M. N.; COSTA, J.A., 2002. Contribuição relativa dos componentes do rendimento para produção de grãos em soja. Pesquisa Agropecuária Brasileira, Brasília, 37:
269-274.

PEIXOTO, C.P.; CÂMARA， G.M.S.; MARTINS, M.C.; MARCHIORI, L.F.S.; GUERZONI, R.A.; MATTIAZZI, P., 2000. Épocas de semeadura e densidade de plantas de soja: I. Componentes da produção e rendimento de grãos. Scientia Agrícola, Piracicaba, 57: 89-96.

PRADO, E.E. do; HIROMOTO, D.M.; GODINHO, V.de P.C.; UTUMI, M.M.; RAMALHO, A.R., 2001. Adaptabilidade e estabilidade de cultivares de soja em cinco épocas de plantio no cerrado de Rondônia. Pesquisa Agropecuária Brasileira, Brasília, 36: 625-635.

REZENDE, P.M.; CARVALHO, E.A., 2007. Avaliação de cultivares de soja (Glycine max (L.) Merrill) para o Sul de Minas Gerais. Ciência e Agrotecnologia, Lavras, 31: 16161623.

RODRIGUES, O.; DIDONET, A.D.; LHAMBY, J.C.B.; BERTAGNOLLI, P.F.; LUZ, J.S.da., 2001. Resposta quantitativa do florescimento da soja à temperatura e ao fotoperíodo. Pesquisa Agropecuária Brasileira, Brasília, 36: 431-437.

WANG, Z.; REDDY, R.V.; ACOCK, M.C., 1998. Testing for early photoperiod insensitivy in soybean. Agronomy Journal, Madison, 90: 389-392. 